\title{
Compact CP Feed Broadband Microstrip Patch Antenna for Wireless Applications
}

\author{
${ }^{1}$ Vivek Singh Rathor, ${ }^{2}$ J.P.Saini \\ ${ }^{I}$ Research Scholar, MEWAR University, Rajasthan, India \\ ${ }^{2}$ Principal, Madan Mohan Malviya Engineering College, Gorakhpur (U.P), India
}

\begin{abstract}
This paper presents a very small size microstrip patch antenna Suitable for WLAN and Wi MAX application. The radiating element of the proposed antenna consists of Kite symbol patch using dielectric substrate 4.2, loss tangent .0012 and having the same substrate height 1.6mm.The compact size antenna of dimension $(14 \mathrm{~m} \times 18.6 \mathrm{~mm} \times 1.6 \mathrm{~mm})$ employed single layer coaxial probe feed. The computer simulation results show that the antenna can realize wide band characteristics. Proposed antenna covers $3.189 \mathrm{GHZ}-4.601 \mathrm{GHZ}$ achieving 36.2\% of impedance bandwidth in one band and other band ranges from 4.655GHZ-8.29GHZ (impedance bandwidth of $56.165 \%$ ).
\end{abstract}

Keywords: Microstrip antenna, wide band, kite shape, IE3D.

\section{Introduction:}

The demand for small antennas in wireless communication in recent years has increased the interest of researchers on compact microstrip antenna design among microwaves and wireless engineers. the explosive growth of wireless system and booming demand for a variety of new wireless application, it become important to design wideband and high gain antennas to cover a wide frequency range For a wireless telecommunication device, a small and light weight antenna is likely to be preferred. For this purpose small size, light weight Compact Microstrip antenna is one of the most suitable antenna. [3]

Microstrip patch antennas are popular for their well-known attractive features of low profile, light weight, and compatibility with monolithic microwave integrated circuits (MMICs). The main disadvantage of this microstrip antenna narrow bandwidth, which is due to the resonant nature of the patch structure.[4] Conventional microstrip antennas in general have a conducting patch printed on a grounded microwave substrate, and have the attractive features of low profile, light weight, easy fabrication, and conformability to mounting hosts.[1] However, conventional microstrip patch antenna suffers from very narrow bandwidth, typically about $5 \%$ bandwidth with respect to the center frequency. This poses a design challenge for the microstrip antenna designer to meet the broadband techniques [3]

Wireless local area network (WLAN) came into picture because of its high data transmission rate and has wide range of applications in modern electronic communication systems, such as desktop computers, mobile phones, personal digital assistants, etc. For these applications, compact microstrip antennas for WLAN operation have been required recently [7]

So we want a antenna which offers a low profile, wide bandwidth, high gain and compact antenna element. Among these standards, the following frequency bands can be mentioned: (1) PCS-1900 requires a band of 1.85-1.99 GHz; (2) IEEE 802.11b/g requires a band of 2.4-2.484 GHz; (3) IEEE 802.11a requires a band of 5.15-5.35 GHz and an additional band of 5.725-5.825 GHz; (4) HiperLAN2 requires a band of 5.47$5.725 \mathrm{GHz}$ besides the band of $5.15-5.35 \mathrm{GHz} \cdot[2,6,7,12]$

To overcome the above problem, a microstrip antenna structure with a typical Kite symbol shaped patch is proposed which exhibits good impedance bandwidth in two bands of $36.2 \%$ and $56.165 \%$ which is suitable for Wi-MAX and WLAN (upper band application).

\section{Antenna Design}

The dielectric constant of the substrate is closely related to the size and the bandwidth of the microstrip antenna. Low dielectric constant of the substrate produces larger bandwidth, The resonant frequency of microstrip antenna and the size of the radiation patch can be similar to the following formulas while the high dielectric constant of the substrate results in smaller size of antenna [1].The Length of ground plane of Antenna is $24 \mathrm{~mm}$ and Width is $28.2 \mathrm{~mm}, \mathrm{~L} \& \mathrm{~W}$ of the patch is $14 \mathrm{~mm} \& 18.6 \mathrm{~mm}$.

The patch width, effective dielectric constant, the length extension and also patch length are given by 


$$
W=\frac{c}{2 f \sqrt{\varepsilon_{r}}}
$$

where $\mathbf{c}$ is the velocity of light, $\varepsilon_{r}$ is the dielectric constant of substrate, $f$ is the antenna working frequency, W is the patch non resonant width, and the effective dielectric constant is $\varepsilon_{\text {eff }}$ given as,

$\varepsilon_{e f f}=\frac{\left(\varepsilon_{r}+1\right)}{2}+\frac{\left(\varepsilon_{r}-1\right)}{2}\left[1+10 \frac{H}{W}\right]^{-\frac{1}{2}}$

The extension length $\Delta$ is calculates as,

$$
\frac{\Delta L}{H}=0.412 \frac{\left(\varepsilon_{\text {eff }}+0.300\right)\left(\frac{W}{H}+0.262\right)}{\left(\varepsilon_{\text {eff }}-0.258\right)\left(\frac{W}{H}+0.813\right)}
$$

By using above equation we can find the value of actual length of the patch as,

$$
L=\frac{c}{2 f \sqrt{\varepsilon_{e f f}}}-2 \Delta L
$$

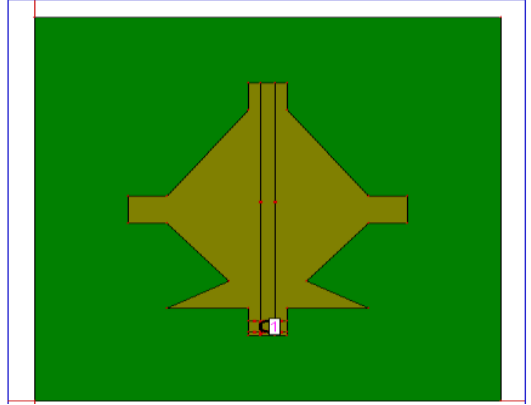

Figure 1. Top view of the microstrip patch antenna

\section{Simulated Results}

In this paper a wideband microstrip antenna with compact size is presented which gives two bands of bandwidth of $36.2 \%$ and $56.165 \%$. These bandwidths cover the frequency bands of Wi-MAX and WLAN (upper band) application. Figure 2 shows the return loss graph of microstrip antenna depicting the multi resonant points. Figure 3 shows the graph of VSWR which should be less than 2.Fig 4 shows the smith chart of the proposed design. Figure 5 shows 3D radiation pattern and Figure 7 shows the Efficiency Vs Frequency curve which shows a high antenna efficiency of about $90 \%$ and radiating efficiency of about $95 \%$ Fig 8 shows the gain $\mathrm{v} / \mathrm{s}$ frequency in which the max gain is around $4 \mathrm{dBi}$ and Maximum Directivity of $6.5 \mathrm{dBi}$.

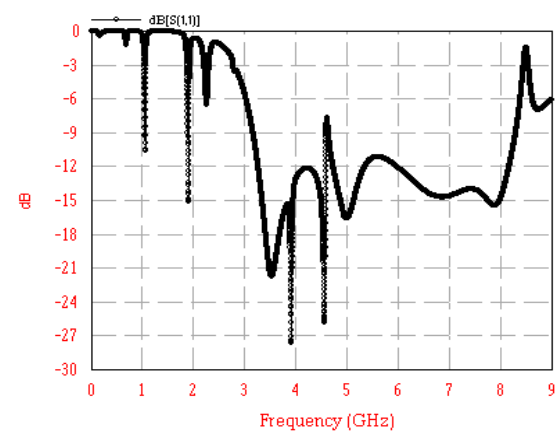

Figure 2. Return loss plot of the microstrip patch antenna 


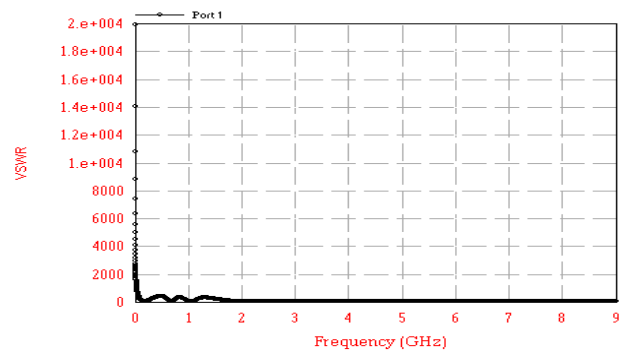

Figure 3. VSWR plot of the microstrip patch antenna.

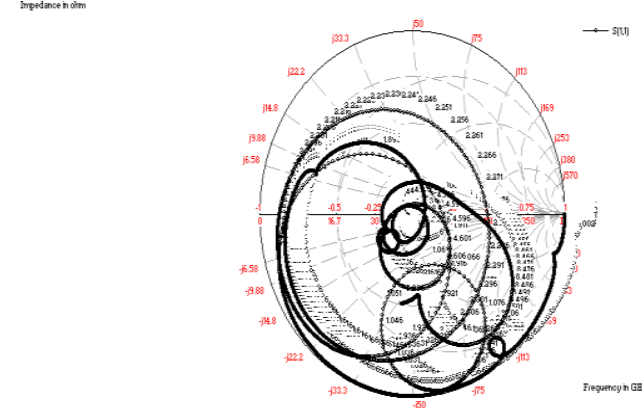

Figure 4. Smith chart of the microstrip patch antenna.

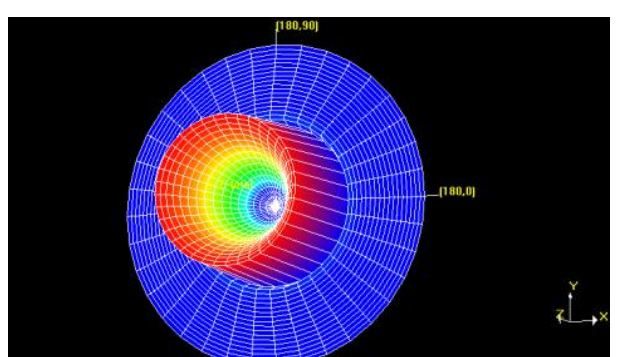

Figure 5. 3D Radiation pattern plot of the microstrip patch antenna Axial-Ratio Vs. Frequency

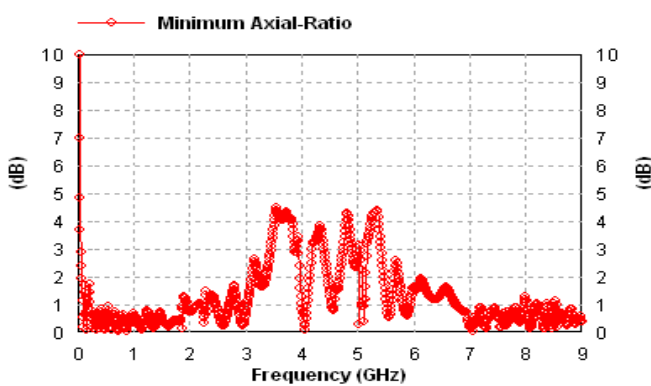

Figure 6. Axial ratio of the microstrip patch antenna Efficiency Vs. Frequency

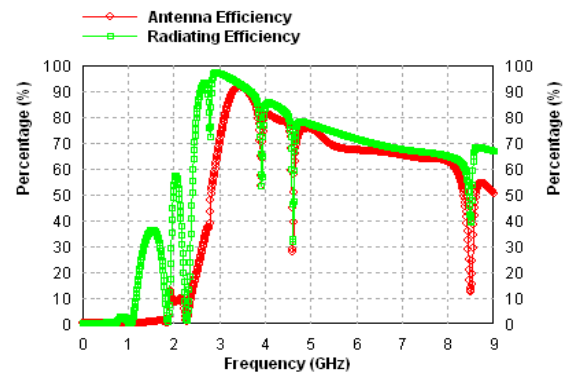

Figure 7. Efficiency plot of the microstrip patch antenna 


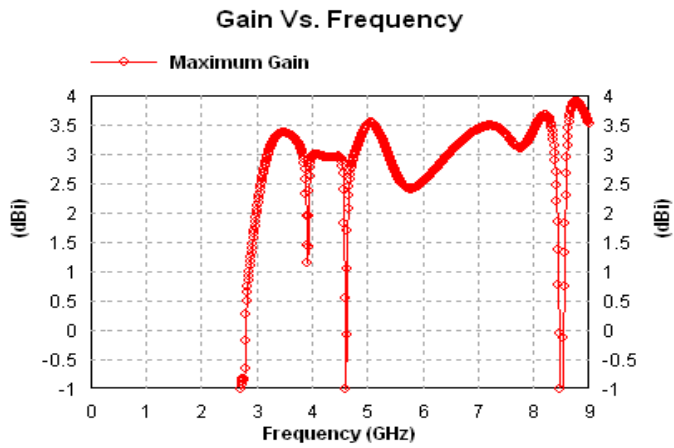

Figure 8. Maximum gain plot of microstrip patch antenna

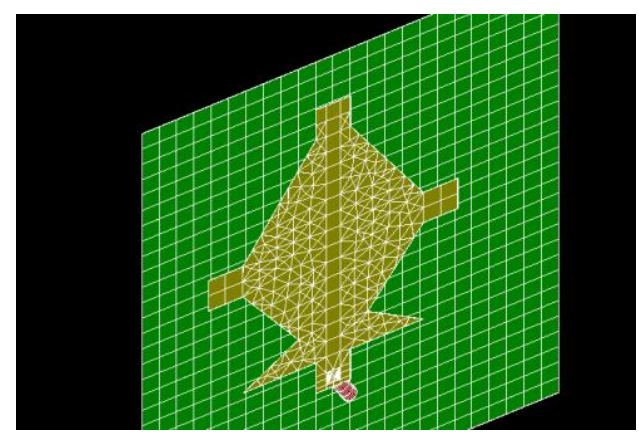

Figure 9. Design of the microstrip patch antenna on IE3D

Directivity Vs. Frequency

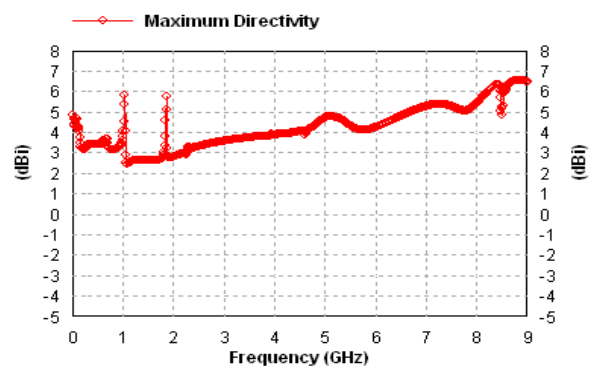

Figure 10. Directivity plot of microstrip patch antenna.

\section{Conclusion:}

In this paper a compact size microstrip antenna has been designed having good impedance matching as well as high antenna efficiency of about of about $90 \%$ is achieved. The proposed antenna have larger impedance bandwidth of $36.2 \%$ and $56.165 \%$ covering the frequency range from .189GHZ - 4.601GHZ and 4.655GHZ8.29GHZ which is suitable for Wi-MAX and WLAN (upper band application).

\section{References:}

[1] M. Abbaspour and H. R. Hassani "Wideband star-shaped microstrip patch antenna" Progress In Electromagnetics Research Letters, Vol. 1, 61-68, 2008

[2] W. Ren "Compact dual-band slot antenna for 2.4/5ghz wlan applications" Progress In Electromagnetics Research B, Vol. 8, 319327,2008

[3] M. T. Islam,M. N. Shakib and N. Misran "Design analysis of high gain wideband L-probe fed microstrip patch antenna" Progress In Electromagnetics Research, PIER 95, 397-407, 2009

[4] S. Maci and G. BifJi Gentili "Dual-Frequency Patch Antennas" IEEE Antennas and Propagation Magazine, Vol. 39, No. 6, December 1997

[5] ZAAKRI Safa, ZENKOUAR Lahbib “Conception of Bi-band Rectangular Microstrip Array Antenna” Journal of Microwaves, Optoelectronics and Electromagnetic Applications, Vol. 12, No. 1, June 2013

[6] Xiaofei Shi, Zhihong Wang, Hua Su, Yun Zhao, "A H-type Microstrip Slot Antenna in Ku-band Using LTCC Technology with Multiple Layer Substrates,” Proc. IEEE, Vol. 978-1, pp. 7104 - 7106, 2011.

[7] U. Chakraborty, S. Chatterjee, S. K. Chowdhury, P. P. Sarkar "A compact microstrip patch antenna for wireless communication" Progress In Electromagnetics Research C, Vol. 18, 211-220, 2011. 
[8] H. Sabri and Z. Atlasbaf "Two novel compact triple band microstrip annular-ring slot antenna for PCS-1900 and WLAN applications."Progress In Electromagnetics Research Letters, Vol. 5, 87-98, 2008

[9] Ramadan, A., K. Y. Kabalan, A. El-Hajj, S. Khoury, and M. Al-usseini, "A reconfigurable U-Koch microstrip antenna for wireless applications," Progress In Electromagnetics Research, PIER 93, 355-367, 2009.

[10] Kawei Qian and Xiaohong Tang, "Compact LTCC dual-band circularly polarized perturbed hexagonal microstrip antenna," IEEE Antennas and Wireless Propagation Letters, Vol. 10 pp. 1212-1215, 2011

[11] K. Kumar and N. Gunasekaran, “A novel wideband slotted mm wave microstrip patch antenna,” Proc. IEEE Vol. 987-1. pp. 10-14, 2011.

[12] D. Xi, L. H. Wen, Y. Z. Yin, Z. Zhang, and Y. N. Mo "A Compact dual inverted C Shaped slots antenna for WLAN application" Progress In Electromagnetics Research Letters, Vol. 17, 115-123, 2010

[13] M. T. Islam, M. N. Shakib and N. Misran, "Broadband E-H shaped microstrip patch antenna for wireless systems," Progress In Electromagnetics Research, PIER 98, 163-173, 2009.

[14] Kasabegoudar, V. G. and K. J. Vinoy, "A broadband suspended microstrip antenna for circular polarization," Progress In Electromagnetics Research, PIER 90, 353-368, 2009

[15] Alloyed, M. N. Kamjani, and M. Shobeyri, "A novel cross-slot geometry to improve impedance bandwidth of microstrip antennas," Progress In Electromagnetics Research Letters, Vol. 4, 63-72, 2008.

[16] G. M. Zhang, J. S. Hong and B. Z. Wang, "Two novel band-notched UWB slot antennas fed by microstrip line," Progress In Electromagnetics Research, PIER 78, 209-218, 2008.

[17] Yu, A. and X. X. Zhang, "A method to enhance the bandwidth of microstrip antennas using a modified E-shaped patch," Proceedings of Radio and Wireless Conference, 261-264, Aug. 10-13, 2003.

[18] D. M. Pozar, “Microstrip Antennas,” Proc. IEEE, vol. 80, No. 1, pp. 79-81, January 1992.

[19] Ram Singh Kushwaha, D.K.Srivastava, J.P.Saini “Compact Triple Band Slotted Microstrip Patch Antenna” International Journal of Engineering Science and Technology (IJEST), Vol. 4 No.03, March 2012.

[20] K.Shambavi, "Gain and Bandwidth Enhancement Technique in Square Microstrip Antenna for WLAN application", Asia-Pacific Microwave Conference 2007, pp.4284-4287.

[21] C.A. Balanis, “Antenna theory”, John Wiley, 1982, pp 727-734.

[22] Bahl, I.J. and Bharatia, P. "Microstrip Antennas", Artech House, 1980

[23] Girish Kumar \& K.P.Ray "Broad Band Microstrip Antenna”, Artech House, USA, 2003, Chapter 1, pp.1-21

\section{AUTHOR PROFILES:}

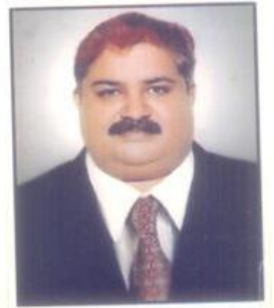

Born on $24^{\text {th }}$ of Aug 1969, Er. Vivek Singh Rathor has completed his bachelor degree in Electronics from renowned Nagpur University, Maharashtra, India, and then he earned his Master degree in the area of System Engineering from DayalBagh University AGRA. He is having vital experience of around 16 years in the field of Academics and Research.

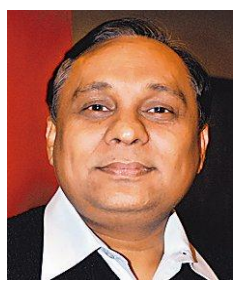

Born on 26th of June 1966, Prof. J.P. Saini has completed his bachelor degree in Electronics and communication from renowned KNIT Sultanpur (UP) India, and then he earned his Master degree from IIT, Kanpur, (UP) India and Ph.D. in Electronics Engineering from Dr. RML Avadh University, Faizabad. He is having total 129 research papers published referred national \& international journals and conferences. Presently, he is working as Principal, Madan Mohan Malaviya Engineering College, Gorakhpur. 